$10-2019$

\title{
Binge-watching behaviours: The impact on medical students in Pakistan
}

Zouina Sarfraz

Fatima Jinnah Medical University. Lahore

Muzna Sarfraz

King Edward Medical University. Lahore

Azza Sarfraz

Aga Khan University, azza.sarfraz@aku.edu

Follow this and additional works at: https://ecommons.aku.edu/

pakistan_fhs_mc_women_childhealth_paediatr

Part of the Medicine and Health Sciences Commons, and the Social and Behavioral Sciences

Commons

\section{Recommended Citation}

Sarfraz, Z., Sarfraz, M., Sarfraz, A. (2019). Binge-watching behaviours: The impact on medical students in Pakistan. JPMA. The Journal of the Pakistan Medical Association, 69(10), 1577-1577.

Available at: https://ecommons.aku.edu/pakistan_fhs_mc_women_childhealth_paediatr/919 


\title{
STUDENTS' CORNER LETTER TO THE EDITOR
}

\section{Binge-Watching Behaviours: The Impact on Medical Students in Pakistan}

\author{
Zouina Sarfraz, ${ }^{1}$ Muzna Sarfraz, ${ }^{2}$ Azza Sarfraz ${ }^{3}$
}

Madam, binge-watching is an area of pressing concern today; it constitutes a prevalent phenomenon where individuals who are part of medical institutions in Pakistan watch endless episodes of the same television series in a row, via digital streaming websites and applications such as Netflix and iflix. Binge watching is essentially defined as watching the same television programme in a row, wherein it constitutes a widespread phenomenon. ${ }^{1}$ However, very little is known about the psychological factors that underlie this behaviour. With the paucity of currently available studies, most focus on the potential harmlessness that these habits have on the still-developing human mind. It ought to be brought to attention that there is some sense of addiction to this habitual behaviour that medical students depict in Pakistan, despite the lack of uniqueness of the impact of binge-watching television shows. It was identified via content analysis that binge-watching features three unique dimensions that include watching motivations that relate to the underlying reason that students binge watch. Watching engagement relates to the incessant need that motivates students to resume their habits to view binge-watching television shows that include Game of Thrones, Grey's Anatomy, Black Mirror, and others; the structural characteristics of television shows are key aspects that keep students addicted in a realm of reality. ${ }^{1}$ At this juncture, it is imperative to note that academic research has only just commenced defining it as bingewatching(watching more than two episodes of the same television at one time). However, there are associated factors that require merit. The ground realities and perplexities that prevail in medical students have become more than evident with the impact of academic achievement and its correlation to depressive symptoms among them. ${ }^{2}$ In addition, it is key to link that obesity

1Fatima Jinnah Medical University. Lahore, 2King Edward Medical University. Lahore, ${ }^{3}$ Aga Khan Medical University. Karachi, Pakistan.

Correspondence: Zouina Sarfraz. Email: zouinasarfraz@gmail.com rates have increased tremendously due to addiction inducing habits such as these as compared to the $1980 \mathrm{~s}^{3}$ Laboratory and epidemiological studies link bingewatching to increases in weight, food intake, and eventually adiposity.4,5 Viewing time should be considered as a biological marker of assessing bingewatching and relating it to engage in similar behavioural engagements. ${ }^{6}$ If one were to relate all these factors in terms of engagement dimensions and relate them to binge-watching, this would only give further support to the notion that medical students are potential precursors to the problematic viewing time that is rampant in the young medical community in Pakistan.

Acknowledgement: We would like to acknowledge that research-based information was used to draft this letter.

Disclaimer: No disclaimer is intended.

Conflict of Interest: There are no intended conflicts of interest.

Funding Disclosure: There are none to declare.

\section{References}

1. Flayelle $M$, Maurage $P$, Billieux J. Toward a qualitative understanding of binge-watching behaviours: $A$ focus group approach. J Behav Addict. 2017; 6:457-71.

2. Boudali M, Hamza M, Halayem S, Bouden A, Belhadj A. Time perception and binge watching among medical students with depressive symptoms. In Euro Neur psyc pharma. 2017; 27: S8112.

3. Hruby A, Hu FB. The epidemiology of obesity: a big picture. Pharmacoeconomics. 2015; 33:673-89.

4. Chapman CD, Nilsson VC, Thune HÅ, Cedernaes J, Le Grevès M, Hogenkamp PS. Watching TV and food intake: the role of content. PLoS One. 2014; 9:e100602.

5. Braude L, Stevenson RJ. Watching television while eating increases energy intake. Examining the mechanisms in female participants. Appetite. 2014; 76:9-16.

6. Andrade-Gómez E, García-Esquinas E, Ortolá R, Martínez-Gómez D, Rodríguez-Artalejo F. Watching TV has a distinct sociodemographic and lifestyle profile compared with other sedentary behaviours: A nationwide population-based study. PloS one. $2017 ; 12: \mathrm{e} 0188836$.

doi:10.5455/JPMA.30497 